\title{
Application of Digital Image Processing to Determine the Properties of Aggregates and Soil using MATLAB: A Case Study

\author{
${ }^{1}$ Department of Civil Engineering, College of Engineering, Shiv Nadar University, Greater Noida - 201 314, Uttar Pradesh, India.
} \\ M.C. Bathula1,*, S.V.H. Madiraju²
}

${ }^{2}$ Dept. of Civil Engineering, College of Engineering, VNR Vignana Jyothi Institute of Engineering and Technology, Hyderabad - 500 090, Telangana, India.

\section{A R T IC LE DET A I L S}

Article history:

Received 16 February 2021

Accepted 08 March 2021

Available online 04 April 2021

\section{Keywords:}

Digital Image Processing

MATLAB

Soil

Aggregate Properties

\begin{abstract}
A B S T RAC T
The vital physical characteristics of aggregates used in engineering and for interpretation of the genesis of naturally occurring sediment are shape and size of rocks. The mineralogical and physical composition of the rock is necessary to cater to the interaction within bounded space and soundings. Several image processing programs are available to measure the size and shape of various types of objects. The accuracy and reproducibility of the results of these imaging methods could be bettered. This paper aims to determine the aggregate dimension and volume to space behaviors through image processing tools. This study is extended investigation of the coarse aggregate shape properties such as area, volume, center of gravity (CG), elongation and flakiness index. Also, this paper discuss the development of an easy to use image processing tool to determine the shrinkage of soils due to lack of moisture content either because of natural ways/artificial ways. Two different types of soils including first sample near the SNU lake and second sample near Business Management School at Shiv Nadar University (SNU), India were collected. The samples were oven-dried over a period and shrinkage values were determined by Digital Image Processing (DIP) using MATLAB. The results are compared to wax-water method (manual method) results of shrinkage. The properties found by DIP method are reasonably agreeable for multiple aggregates and minor percentage differences in the soil shrinkage results.
\end{abstract}

\section{Introduction}

A digital image is a numerical representation, normally binary, of a twodimensional image. DIP is the process of performing image processing on digital images with the use of computer algorithms. It could be employed to determine and evaluate properties of aggregates, rocks with the help of images captured. These processes are advantageous as they are NonDestructive Tests (NDT) and we can assess and access the materials which are inaccessible, or which are still in use. It also reduces the amount of time and energy necessary in carrying out these processes manually. DIP is easy to use and economical. Image processing is employed in this paper to obtain shrinkage of soil due to loss in moisture content by natural or artificial ways. The Wax-water method is a manual method used to find the shrinkage values of soil [1,2]. Soil shrinkage is, for the most part, kept to the upper layers of soil. Shrinkage splits are caused by the decrease in soil dampness content through dissipation from the soil surface in dry atmospheres, bringing down the groundwater table, and drying up of soil by trees amid transitory droughts in general muggy atmospheres. Shrinkage is influenced by properties of soil including moisture content, plasticity index, mineralogy, and to some extent permeability. Shrinkage and swelling lead to failure of soils due to change in stresses and lead to appearances of cracks in civil structures [3]. This study provides step by step procedure followed to evaluate the shrinkage in two different kinds of soil available in SNU with varying moisture content when changed from heating using image processing and compare the results with the Waxwater manual method of finding soil shrinkage volume [4]. The processing of data for storage and transmission using digital images is a DIP technique. It extracts information out of images [5]. There is a wide range of applications for image processing such as medical/biological, fingerprints, space image processing, remote sensing applications et cetera [6]. There are some basic functions to be performed that are imperative for producing the required result. These stepwise functions are pre-processing, image acquisition, recognition, interpretation, segmentation, representation, description, problem domain and result [7].

*Corresponding Author:maruti.bathula@outlook.com(Maruti Chowdary Bathula)

\subsection{Aggregate Properties}

a) Grading: Grading refers to the determination of the particle-size distribution for aggregate. Grading limits and maximum aggregate size affect the amount of aggregate used. Cement, water requirements, workability, pumpability, and durability of concrete are also affected by grading limits.

b) Angularity: Angularity is necessary to ensure adequate aggregate interlock and prevent excessive hot mix asphalt deformation under load. Angularity number is the measure of angularity. It is measured as the percentage of voids in the aggregate after compaction.

c) Elongation Index: The particles whose largest length is 1.8 times their mean dimension are elongated. To calculate the elongated index, the weight of elongated particles is expressed as a percentage of the total weight of the sample.

d) Flakiness Index: A flaky particle is the one whose least dimension is 0.6 times the mean size. Flakiness index is the percentage by weight of flaky particles in a sample.

e) Sphericity: It is a measure of the roundness of aggregates. Sphericity is usually defined as the ratio of the surface area of a sphere having the same volume as the particle to the actual surface area of the particle [8].

\subsection{Soil Properties}

a) Moisture Content: The percentage of moisture which is expressed as the ratio of the weight of water to the weight of the dry soil in each mass of soil after oven drying the sample by maintaining a temperature between $105^{\circ} \mathrm{C}$ and $110^{\circ} \mathrm{C}$.

b) Specific Gravity: The ratio of the weight of soil sample in the air to the weight of distilled water of the same volume in the air at the same temperature. Specific Gravity is used to calculate other soil properties like void ratio, degree of saturation, and weight-volume relationship.

c) Permeability: The ability of the soil to transmit water and air through the soil. It is expressed as the coefficient of permeability. The rate of flow under laminar flow conditions through a unit crosssectional area of the porous medium under the unit hydraulic gradient is defined as the coefficient of permeability. The knowledge 
of this property is much useful in solving problems involving the yield of water-bearing strata, seepage through earthen dams, the stability of earthen dams, and embankments of canal banks affected by seepage, settlement et cetera.

d) Shrinkage-Limit: Every type of soil undergoes volumetric reduction when exposed to natural sunlight or by artificial heating. Shrinkage limit is the moisture content percentage limit of soil after which no volume change occurs even if the moisture content drops further [9].

\subsection{Digital Image Process}

DIP has changed the way the properties of aggregates are found. A lot of time and destruction are involved while finding out the properties [10]. DIP techniques are widely used to analyze the particle shape characteristics of aggregate due to reduced time and its NDT characteristics [11]. Properties of particles that are not accessible are also easily found. Grading curves are either found by finding volume by 2-D image information or by combining two images to get 3-D information [12]. Angularity, sphericity, elongation index, and flakiness index are found hassle-free by introducing parameters to the information from the 2-D images [13].

\section{Experimental Methods}

Digital image processing could be used to find many physical properties of aggregates. It comes under NDT and consumes lesser time to derive results and hence this method is selected to find the volumetric shrinkage of soil due to loss of moisture content either by the natural or artificial method. This paper will also discuss the best algorithms that could be used to find aggregate properties such as angularity, sphericity, flakiness index, and elongation index using MATLAB. The shape factor is found by using digital image processing over a regular object with known dimensions. The bounding box of an irregular boulder is determined using DIP and to extract its maximum length, breadth, and center of gravity of the boulder. The properties of multiple aggregates such as length, breadth, area, volume, the center of gravity, elongation index, flakiness index, and sphericity using DIP are calculated and the results were compared with conventional results. A code was developed to extract the volumetric shrinkage of two different kinds of soil available in SNU for varying moisture content by oven drying the sample and compare the results to the conventional method of wax-water method of finding shrinkage is determined. All the raw materials such as aggregates and soil are collected from Shiv Nadar University. Different types of soil are collected from two points at the University for Comparison. One sample is taken from the lakeside of the university and another sample is taken from the Business Management block (BMS)

\section{Results and Discussion}

\subsection{Extracting Information from a Regular Object}

To familiarize readers with the code developed, the physical properties of a regular object are found with known data. The accuracy and ease of use are checked with this experiment and pixel to mm conversion is made by determining the scale factor [14]. The camera is placed at a fixed known height. A fixed height gives us the same scale factor. White chart paper is used as a background to get a clear view of the objects placed and avoid any sort of unwanted discrepancies during capture. Shadows were avoided by adjusting the light as much as possible [15].

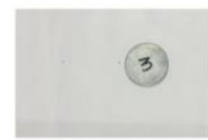

RGB image of the cap

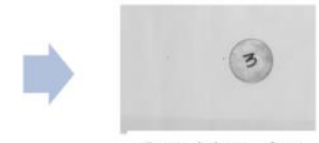

Greyscale image of cap
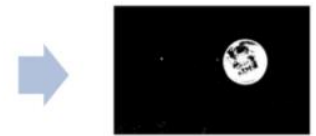

Binary with noises

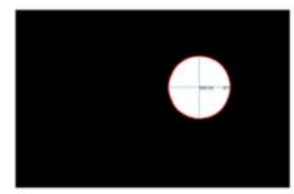

Boundary detection of the binary

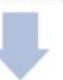

Bound

Fig. 1 Chronological order of steps to extract information from the regular object image

https://doi.org/10.30799/jacs.234.21070104

The computing programming language used in this paper to compute the necessary information of various civil engineering materials is MATLAB. Figs. 1 and 2 represent logical steps in chronological order carried out to extract information from the regular objects. The regular objects captured for the purpose are a cap and a disk with known dimensions. Minor percentage error of under $2 \%$ in the length and area from DIP when compared to the real length and surface area of the objects due to the placement of objects and due to unavoidable specks of shadows.

The RGB image is read and converted into a greyscale image and global threshold level is found to convert the intensity image to a binary image

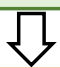

Using the level found, binary image is extracted

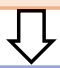

Holes and other disturbances are removed and object in the binary image is separated from its background

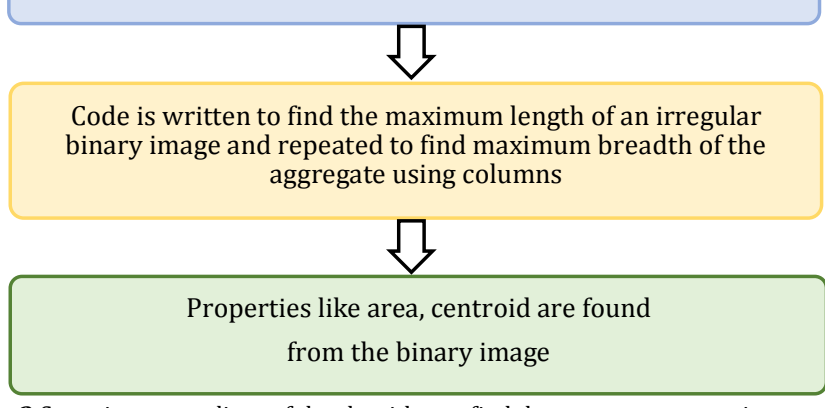

Fig. 2 Stepwise proceedings of the algorithm to find the aggregate properties

\subsection{Extracting Information from an Irregular Boulder}

After familiarizing with the code in MATLAB and establishing the scale factor using a regular object, the accuracy of length, breadth detection of an irregular object must be built as all the civil engineering materials used are irregular [16]. Therefore, an irregular boulder is used to find the accurate maximum length, maximum breadth, and centroid. A similar setup is used as used to capture a regular object with white chart paper as a background. The height of the camera is the same as used for regular objects and care is taken to avoid major shadows. An irregular small boulder is captured using this set-up. MATLAB is used to extract the dimensions of the irregular boulder. A slightly modified version of the code is used to derive the maximum length and breadth of the irregular boulder. Maximum length and breadth were found and compared the results with manual length and breadth of the boulder. The centroid is also found and plotted concerning the origin. Figs. 3 and 4 represents stepwise proceedings of steps of an algorithm to extract information from irregular objects. The percentage of error when both DIP and conventional methods are compared is around $2-3 \%$ as per the results from Table 1 . The lack of complete precision is due to some unavoidable shadows.

Table 1 Comparison of properties of the single irregular small boulder by DIP and conventional methods

\begin{tabular}{lll}
\hline & DIP $(\mathrm{cm})$ & Conventional $(\mathrm{cm})$ \\
\hline Length & 8.80 & 9.2 \\
Breadth & 6.34 & 6.5 \\
\hline
\end{tabular}

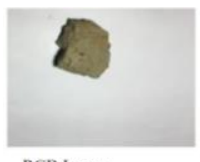

RGB Image
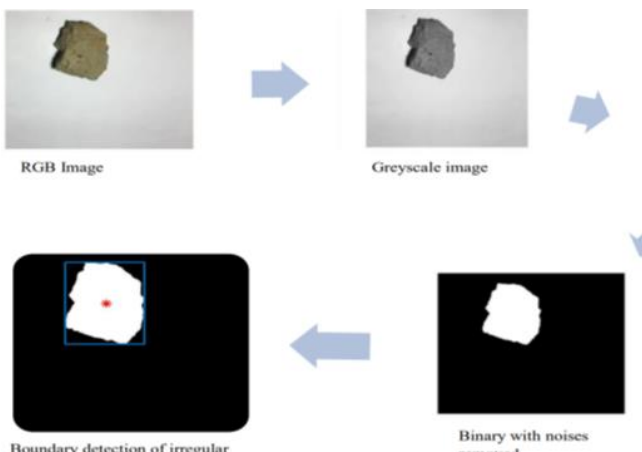

Boundary detection of irregular
boulder and centroid position

Fig. 3 Chronological order of steps to extract information from an image of an irregular boulder 
The RGB image is read and converted into a greyscale image and global threshold level is found to convert the intensity image to a binary image

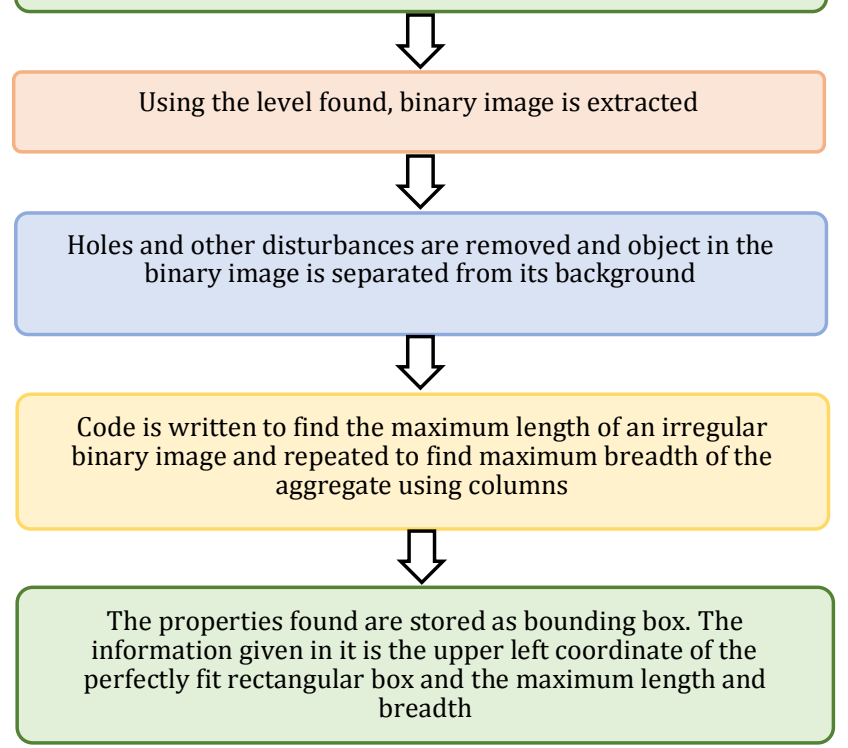

Fig. 4 Stepwise proceedings of the algorithm to store the properties as bounding box

\subsection{Extracting Information from Multiple Coarse Aggregates}

Extract information from a bulk of coarse aggregates at the same time in one image is timesaving and DIP gives accurate results of aggregate properties [17]. MATLAB codes on both regular and irregular single aggregates are tested. Improving and extending the code can achieve good results of multiple coarse aggregate properties such as maximum length, maximum breadth, area, volume, centroid, elongation ratio, flakiness ratio, and sphericity of the coarse aggregates [18]. Volume from 2D imaging is tedious and proved methods are used to find volume, sphericity, flakiness ratio, and elongation ratio using 2D imaging as per Mora et al 2000. Thickness and volume are estimated by an assumption that aggregates from the same source have more or else the same characteristics. This mean thickness can be estimated from the breadth of the aggregates.

mean thickness $=\lambda \times$ breadth

$\lambda$ depends on the flakiness of aggregates and it is expressed as

$$
\lambda=\operatorname{M} \rho \times \Sigma(\text { area } \times \text { breadth }) \text { ni }=1
$$

volume $=\lambda \times$ breadth $\times$ area

The flakiness ratio is expressed as $\lambda$ determined as it represents the mean thickness/breadth ratio of the aggregate sample. Elongation ratio is expressed as length to breadth ratio.

$$
\text { Sphericity }=\sqrt{ }\left(\text { thickness } \times \text { breadth } / \text { length }^{2}\right)
$$

Most of the results are compared to the results from manual conventional methods to determine the accuracy and compute the percentage of error. Coarse aggregate is collected from the lab and sieve analysis was performed on the sample. Sample for capturing is chosen by taking aggregates from every sieve to have the right mix of samples of different sizes. A white chart paper is spread, and aggregates are placed over it. Care is taken such that there is no overlap of aggregates. Fixed height is used as used for the previous two pictures to get the same scale factor. Shadows are avoided as much as possible and pictures are to have a good definition.

Tests performed on the aggregates. Sieve analysis is performed to get the right sample for DIP. Flakiness and Elongation index and specific gravity tests are performed on the coarse aggregates from which the sample is collected. Table 2 shows the results of the tests on coarse aggregates. Stepwise proceedings of the algorithm to find the properties of multiple coarse aggregates are represented in Fig. 5. The chronological order of steps to extract information from an image of multiple aggregates is represented in Fig. 6. From Table 2, Flakiness index and elongation index are found.

$$
\text { Flakiness index }=\frac{W_{2}}{W_{1}} \times 100=\frac{0.526}{4.935} \times 100=10.879 \%
$$$$
\text { Elongation index }=\frac{W_{3}}{W_{1}} \times 100=\frac{0.566}{4.935} \times 100=11.7 \%
$$$$
\text { https://doi.org/10.30799/jacs.234.21070104 }
$$

Table 2 Results of elongation and flakiness index experiment

\begin{tabular}{llll}
\hline Sieve size $(\mathrm{mm})$ & Total mass $(\mathrm{Kg})$ & Elongation & Flakiness \\
\hline $6.5-10$ & 0.15 & 0.084 & 0.024 \\
$10-12.5$ & 0.393 & 0.148 & 0.053 \\
$12.5-16$ & 0.776 & 0.172 & 0.064 \\
$16-20$ & 1.307 & 0.1 & 0.149 \\
$20-25$ & 2.209 & $0 . .62$ & 0.236 \\
Total & $\mathrm{W}_{1}=4.935$ & $\mathrm{~W}_{3}=0.566$ & $\mathrm{~W}_{2}=0.526$ \\
\hline \multicolumn{2}{l}{ Specific gravity of coarse aggregate is $2.76 ;$ Number of coarse aggregate samples $=150$}
\end{tabular}

The RGB image is read and converted into a greyscale image and global threshold level is found to convert the intensity image to a binary image

Using the level found, binary image is extracted

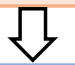

Holes and other disturbances are removed and object in the binary image is separated from its background

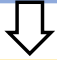

Code is written to find the maximum length of an irregular binary image and repeated to find maximum breadth of the aggregate using columns

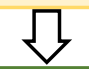

The properties found are stored as bounding box. The information given in it is the upper left coordinate of the perfectly fit rectangular box and the maximum length and breadth specifically for each aggregate

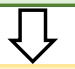

Code is written to calculate the $\lambda$, area, volume, sphericity, elongation, and flakiness ratio for the multiple aggregates in the image based on the formulas given in the introduction

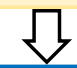

This gives all the final information that we need in $\mathrm{mm}, \mathrm{mm}^{2}, \mathrm{~mm}^{3}$ and so on

Fig. 5 Stepwise proceedings of the algorithm to find the properties of multiple coarse aggregates

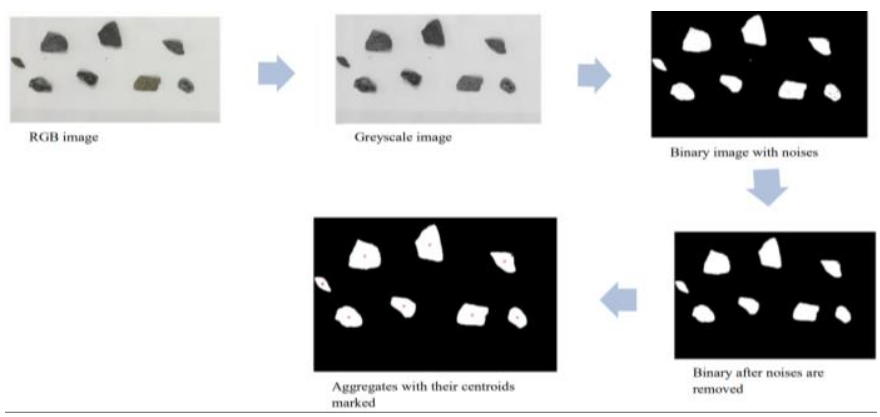

Fig. 6 Chronological order of steps to extract information from an image of multiple aggregates

Table 3 Comparison parameters of coarse aggregates using DIP and conventional methods

\begin{tabular}{lll} 
methods & & Conventional \\
\hline Property & DIP & 27.45 \\
Bulk Volume $\left(\mathrm{cm}^{3}\right)$ & 27.45 & 11.7 \\
Elongation Index $(\%)$ & 14 & 10.879 \\
Flakiness Index (\%) & 31 & Scale factor $=1$ pixel $=0.1828 \mathrm{~mm} ;$ Mass of bulk aggregates $=75.77 \mathrm{~g}$
\end{tabular}

A comparison of parameters of coarse aggregates using both DIP and conventional methods is provided in Table 3. Negligible error is noticed in volume. But elongation and flakiness indices are noticed to have significant errors as the sample size is very small. It can further be improved with the quality of pictures and the removal of complete shadows. 


\subsection{Extracting Information on Volumetric Soil Shrinkage}

Soil shrinkage occurs in expansive soil when the soil dries when heating occurs naturally or through oven drying. Failure occurs in the form of cracks due to volumetric changes in the soil. Therefore, it is important to find a change in the volume of shrinkage to study the damage caused by the soil. Shrinkage depends on the changing moisture content of the soil, mineralogy, plasticity index, pore water pressure, and so forth. DIP can be used to calculate the volumetric changes in soil due to shrinkage as it gives accurate results [19]. DIP shrinkage results are compared with conventional results. The conventional method used to find the shrinkage is the wax-water method which works on the Archimedes principle. The soil sample is collected from two points in SNU (Shiv Nadar University). The first point is right next to the lake and the second point is near BMS (Business management school). The soil was collected from a depth of about $50 \mathrm{cms}$. To reduce the basic soil properties and compare the differences between both the soils laboratory tests are performed. They are, i) grain size analysis (sieve analysis), ii) moisture content, iii) specific gravity, iv) consistency limits (plastic limit, liquid limit, and plasticity index) and v) permeability test. The laboratory tests are performed as per conventional methods as followed by Indian Standard (IS) procedures.

\subsubsection{Grain Size Analysis of the Sample Soils (Sieve Analysis)}

This section provides the results of the grain sieve analysis for lake soil and BMS soil (Tables 4 and 5 respectively), the trend of grain size (mm) and (\%) finer of both lake and BMS soils (Fig. 7), D60, D30, D15 of the lake, and BMS soil (Table 6).

Table 4 Grain sieve analysis observations (lake soil)

\begin{tabular}{lllll}
\hline $\begin{array}{l}\text { I.S. Sieve } \\
\text { Number or } \\
\text { size in mm }\end{array}$ & $\begin{array}{l}\text { Wt. retained in } \\
\text { each sieve }(\mathrm{g})\end{array}$ & $\begin{array}{l}\text { \% retained on } \\
\text { each sieve }\end{array}$ & $\begin{array}{l}\text { Cumulative \% } \\
\text { retained on each } \\
\text { sieve }\end{array}$ & \% Finer \\
\hline 4.25 & 26 & 5.39 & 5.39 & 94.61 \\
2 & 46 & 9.54 & 14.93 & 85.07 \\
1.18 & 46 & 9.54 & 24.47 & 75.53 \\
0.6 & 50 & 10.37 & 34.84 & 65.16 \\
0.425 & 36 & 7.46 & 42.3 & 57.7 \\
0.3 & 6 & 1.24 & 43.54 & 56.46 \\
0.15 & 40 & 8.29 & 51.8 & 48.17 \\
0.075 & 172 & 35.68 & 87.51 & 12.49 \\
Pan & 60 & 12.45 & 100 & 0 \\
\hline
\end{tabular}

Table 5 Grain sieve analysis observations (BMS soil)

\begin{tabular}{lllll}
\hline $\begin{array}{l}\text { I.S. Sieve } \\
\begin{array}{l}\text { Number or } \\
\text { size in mm }\end{array}\end{array}$ & $\begin{array}{l}\text { Wt. retained in } \\
\text { each sieve }(\mathrm{g})\end{array}$ & $\begin{array}{l}\text { \% retained on } \\
\text { each sieve }\end{array}$ & $\begin{array}{l}\text { Cumulative \% } \\
\text { retained on each } \\
\text { sieve }\end{array}$ & Finer \\
\hline 4.25 & 26 & 5.33 & 5.33 & 94.67 \\
2 & 36 & 7.38 & 12.70 & 87.29 \\
1.18 & 40 & 8.20 & 20.10 & 79.10 \\
0.6 & 36 & 7.38 & 28.28 & 71.72 \\
0.425 & 32 & 6.56 & 34.83 & 65.16 \\
0.3 & 6 & 1.23 & 36.06 & 63.93 \\
0.15 & 32 & 6.56 & 42.62 & 57.38 \\
0.075 & 190 & 38.93 & 81.56 & 18.44 \\
Pan & 90 & 18.44 & 100 & 0 \\
\hline
\end{tabular}

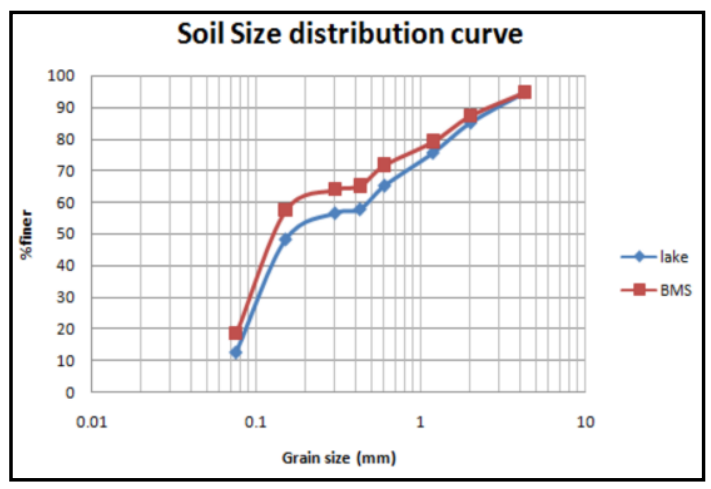

Fig. 7 The trend of grain size $(\mathrm{mm})$ and \% finer of both lake and BMS soils

Table 6 D60, D30, D15 of lake soil and BMS soil

\begin{tabular}{lll}
\hline Size & Lake soil & BMS soil \\
\hline D60 & 0.4789 & 0.21 \\
D30 & 0.1118 & 0.0972 \\
D10 & 0.0697 & 0.0587 \\
\hline
\end{tabular}

\subsubsection{Determining Moisture Content of the Soils}

Initial moisture content is determined by oven drying the samples for one day and taking the weights of normal soil and oven-dried soil. Two samples for each type of soil are used for the test. The average moisture content for lake soil is $5.48 \%$ and the average moisture content of BMS soil is $2.61 \%$ (Table 7 ).

Table 7 Observations derived from moisture content experiment

\begin{tabular}{|c|c|c|c|c|c|}
\hline \multirow[t]{2}{*}{ S.No. } & \multirow[t]{2}{*}{ Sample } & \multicolumn{2}{|c|}{ Lake (g) } & \multicolumn{2}{|c|}{ BMS (g) } \\
\hline & & 1 & 2 & 1 & 2 \\
\hline 1 & $\begin{array}{l}\text { Weight of container with lid } \\
W_{1} \mathrm{~g}\end{array}$ & 14 & 16 & 14 & 16 \\
\hline 2 & $\begin{array}{l}\text { Weight of container with lid + } \\
\text { wet soil } W_{2} \text { g }\end{array}$ & 44 & 44 & 42.5 & 46 \\
\hline 3 & $\begin{array}{l}\text { Weight of container with lid + } \\
\text { dry soil } W_{3} \text { g }\end{array}$ & 42.8 & 42.22 & 42 & 45 \\
\hline 4 & $\begin{array}{l}\text { Water/Moister content } \\
W=\left(W_{2}-W_{3}\right)\left(W_{3}-W_{1}\right) \times 100\end{array}$ & $4.17 \%$ & $6.78 \%$ & $1.78 \%$ & $3.44 \%$ \\
\hline
\end{tabular}

\subsubsection{Determining Specific Gravity of the Soils}

Soil passing through a $4.75 \mathrm{~mm}$ IS sieve is used for the test. Specific gravity is necessary to calculate soil properties like void ratio, degree of saturation. Two samples of each type of soil are used to determine specific gravity. The average specific gravity of lake soil is 2.430 and the average specific gravity of BMS soil is 2.399 (Table 8).

Table 8 Observations of specific gravity experiment

\begin{tabular}{llllll}
\hline S. No. & Observation Number & \multicolumn{3}{l}{ Lake $(\mathrm{g})$} & \multicolumn{3}{l}{ BMS $(\mathrm{g})$} \\
\cline { 3 - 6 } & & 1 & 2 & 1 & 2 \\
\hline 1 & Weight of density bottle $\left(W_{1} g\right)$ & 74.62 & 71.41 & 56.27 & 70.88 \\
2 & $\begin{array}{l}\text { Weight of density bottle + dry soil } \\
\left(W_{2} g\right)\end{array}$ & 91.11 & 90.44 & 72.32 & 86.97 \\
3 & $\begin{array}{l}\text { Weight of bottle + dry soil + water } \\
\text { at the temperature } T_{x}^{0} \mathrm{C}\left(W_{3} \mathrm{~g}\right)\end{array}$ & 182.66 & 184.58 & 165.27 & 184.24 \\
4 & $\begin{array}{l}\text { Weight of bottle }+ \text { water at the } \\
\text { temperature } T_{x}^{0} \mathrm{C}\left(W_{4} \mathrm{~g}\right)\end{array}$ & 172.9 & 173.44 & 156.07 & 174.70 \\
5 & $\begin{array}{l}\text { Specific Gravity } \mathrm{G} \text { at } \mathrm{T}_{\mathrm{x}}{ }^{\circ} \mathrm{C} \\
\mathrm{n}\end{array}$ & 2.44 & 2.41 & 2.34 & 2.46 \\
\hline
\end{tabular}

\subsubsection{Determining Consistency Limits of the Soils}

\subsubsection{Liquid Limit}

Table 9 provides the observations derived from the liquid limit experiment of both soils. Semi-log plot of moisture content (\%) and number of blows in the liquid limit gives the moisture content of lake soil at 25 blows (Fig. 8)

Table 9 Observations from the Liquid limit experiment of both the soils

\begin{tabular}{lllll}
\hline Determination Number & Lake & \multicolumn{3}{l}{ BMS } \\
\cline { 2 - 5 } & 1 & 2 & 1 & 2 \\
\hline Weight of container (g) & 206 & 204 & 202 & 200 \\
Weight of container + wet soil (g) & 356 & 356 & 360 & 360 \\
Weight of container + dry soil (g) & 326 & 328 & 330 & 332 \\
Weight of water (g) & 30 & 28 & 30 & 32 \\
Weight of dry soil (g) & 120 & 124 & 128 & 126 \\
Moisture content (\%) & 25 & 22.58 & 23.43 & 25.35 \\
No. of blows & 17 & 32 & 25 & 18 \\
\hline
\end{tabular}

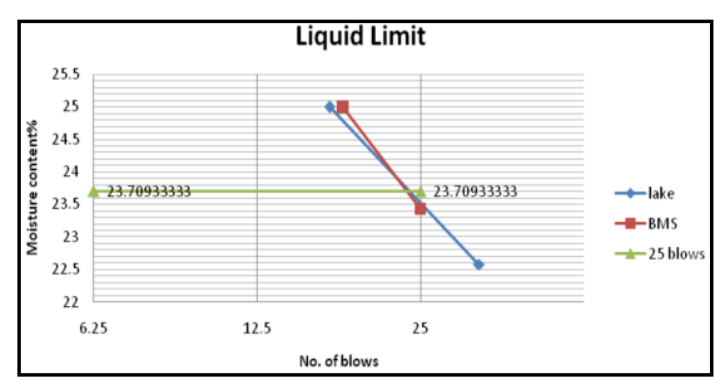

Fig. 8 Semi-log graph plot between moisture content (\%) and the number of blows in the liquid limit

The liquid limit is majorly used to know the stress history and general properties of soil. Two samples of each soil type are taken. The moisture content at which the groove formed by a standard tool into the sample of soil taken in the standard cup, closes for $10 \mathrm{~mm}$ on being given 25 blows is the Liquid limit. The liquid limit of lake soil is $23.71 \%$ and the liquid limit of BMS soil is $23.43 \%$. 


\subsubsection{Plastic Limit}

The plastic limit is the moisture content of the soil at which you can make long thin $3 \mathrm{~mm}$ diameter rolled soil. The soil is well kneed and rerolled until the thread crumbles. Two samples of each soil are used to determining the plastic limit. By the observations in Table 10, the plastic limit of lake soil is $26.51 \%$ and for BMS soil it is $13.69 \%$.

Table 10 Observations from the plastic limit experiment of both the soils

\begin{tabular}{lllll}
\hline Determination Number & Lake (g) & \multicolumn{2}{l}{ BMS (g) } \\
\cline { 2 - 5 } & 1 & 2 & 1 & 2 \\
\hline Weight of container + lid, $W_{1}$ & 202 & 202 & 202 & 204 \\
$\begin{array}{l}\text { Weight of container + lid+ wet } \\
\text { sample, } W_{2}\end{array}$ & 285 & 233 & 233 & 232 \\
$\begin{array}{l}\text { Weight of container + lid +dry } \\
\text { sample, } W_{2}\end{array}$ & 268 & 224 & 230 & 228 \\
$\begin{array}{l}\text { Weight of dry sample }=W_{3}-W_{1} \\
\text { Weight of water in the }\end{array}$ & 66 & 22 & 28 & 24 \\
$\begin{array}{l}\text { soil }=W_{3}-W_{2} \\
\text { Water content }(\%)=\left(W_{3}-W_{2}\right) /\end{array}$ & $25.75 \%$ & 6 & 3 & 4 \\
$\left(W_{3}-W_{1}\right) \times 100$ & & & & \\
\hline
\end{tabular}

Table 11 Observations from the permeability test of both the soils

\begin{tabular}{|c|c|c|c|c|c|c|}
\hline \multicolumn{2}{|c|}{ Failing head permeability test } & \multicolumn{3}{|l|}{ Lake } & \multicolumn{2}{|l|}{ BMS } \\
\hline & & 1 & 2 & 3 & 1 & 2 \\
\hline $\begin{array}{l}\text { Areas of standpipe } \\
\text { (diameter } 5 \mathrm{~cm} \text { ) }\end{array}$ & $\mathrm{a}(\mathrm{cm})$ & 0.1963 & 0.1963 & 0.1963 & 0.1963 & 0.1963 \\
\hline $\begin{array}{l}\text { Cross-sectional } \\
\text { area of soil } \\
\text { specimen }\end{array}$ & $\mathrm{A}\left(\mathrm{cm}^{2}\right)$ & 78.539 & 78.539 & 78.539 & 78.539 & 78.539 \\
\hline $\begin{array}{l}\text { Length of soil } \\
\text { specimen }\end{array}$ & $\mathrm{L}(\mathrm{cm})$ & 12.8 & 12.8 & 12.8 & 12.8 & 12.8 \\
\hline $\begin{array}{l}\text { Initial reading of } \\
\text { standpipe }\end{array}$ & $\mathrm{h} 1(\mathrm{~cm})$ & 80 & 80 & 80 & 80 & 80 \\
\hline $\begin{array}{l}\text { Final reading of } \\
\text { standpipe }\end{array}$ & $\mathrm{h} 2(\mathrm{~cm})$ & 40 & 40 & 40 & 40 & 40 \\
\hline Time & $\mathrm{T}(\mathrm{sec})$ & 195 & 187 & 183 & 303 & 280 \\
\hline $\begin{array}{l}\text { Coefficient of } \\
\text { permeability at } \mathrm{T}\end{array}$ & $\begin{array}{l}\mathrm{k} \\
(\mathrm{cm} / \mathrm{sec})\end{array}$ & $\begin{array}{l}1.1359 \mathrm{x} \\
10^{-4}\end{array}$ & $\begin{array}{l}1.1845 \\
\times 10^{-4}\end{array}$ & $\begin{array}{l}1.2103 \\
\times 10^{-4}\end{array}$ & $\begin{array}{l}7.51 \mathrm{x} \\
10^{-5}\end{array}$ & $\begin{array}{l}7.9 x \\
10^{-5}\end{array}$ \\
\hline
\end{tabular}

\subsubsection{Determination of Coefficient of Permeability of Soils}

The falling head method is used to determine the coefficient of permeability. Permeability is used to determine groundwater flow, seepage through dams, settlement of structures et cetera. The permeability of each soil sample is determined by letting water flow through the soil cylinder using a permeameter. The coefficient of permeability of lake soil is $1.1769 \times 10^{-4}$ and that of BMS soil is $7.705 \times$ $10^{-4}$ from the observations made in Table 11.

After testing the basic soil properties of the two soils collected from the campus, the soil samples are mixed with different quantities of water for varying moisture content and placed in the oven. Samples are dried for 1 , 10, 15 days to observe the extent of shrinkage. Stepwise proceedings of the algorithm to find the shrinkage of soil is represented in Fig. 9.

The RGB image is read and converted into a greyscale image and global threshold level is found to convert the intensity image to a binary image

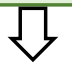

Using the level found, binary image is extracted

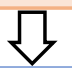

Holes and other disturbances are removed and object in the binary image is separated from its background

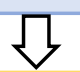

Scale is found automatically as the disk used for soil sample is the same for all with fixed diameter $(45 \mathrm{~mm})$

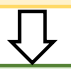

The shrunk part is detected and the area of it is derived in pixels and this is converted to $\mathrm{mm}^{2}$ using the found scale factor

Fig. 9 Stepwise proceedings of the algorithm to find the shrinkage of soil. https://doi.org/10.30799/jacs.234.21070104

Cite this Article as: M.C. Bathula, S.V.H. Madiraju, Application of digital image processing to determine the properties of aggregates and soil using MATLAB: A case study, J. Adv. Chem. Sci. 7(1) (2021) 711-716.
3.4.6 Manual Method of Determining Volumetric Soil Shrinkage and Shrinkage Limit

By oven drying or by natural environment soil losses moisture and it changes from liquid state to plastic state, from plastic state to semi-solid state and then to solid-state. Volumetric changes also occur with varying moisture content. Shrinkage limit is the limit of moisture content at which any moisture change does not cause any more volume change [20]. Disks of the fixed volume are used for the test. The formula used for shrinkage limit is

Shrinkage limit $=\mathrm{W}-\left(\left(\mathrm{V}-V_{0}\right) \times\left(\mathrm{YW} W_{0}\right) \times 100\right.$

where, $\quad W=$ Moisture content of wet soil pat (\%)

$\mathrm{V}=$ Volume of wet soil pat in $\mathrm{cm}^{3}$

$V_{0}=$ Volume of dry soil pat in $\mathrm{cm}^{3}$

$W_{0}=$ Weight of oven-dry soil pat in $g$.

The volume shrunk is calculated from $\left(\mathrm{V}-V_{0}\right)$. The volume of dry pat is determined by the principle of Archimedes

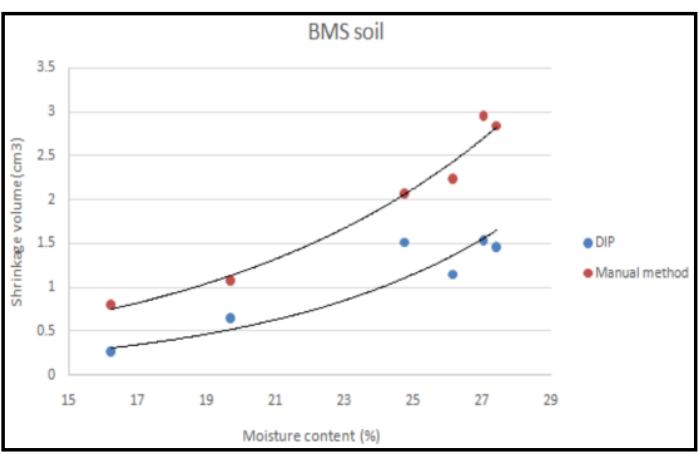

Fig. 10 Shrinkage volume with varying moisture content using both DIP and manual methods of BMS soil

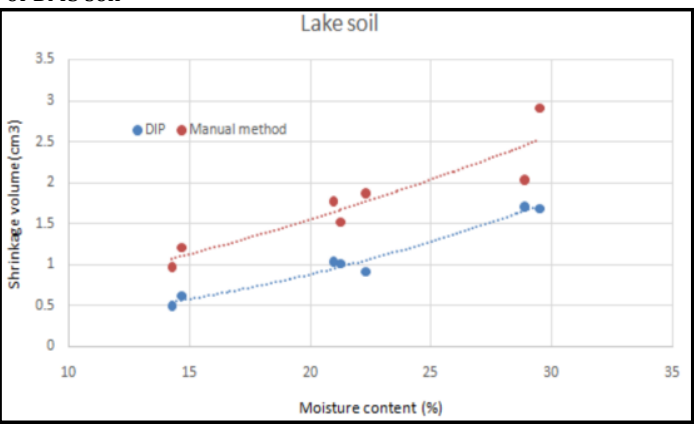

Fig. 11 Shrinkage volume with varying moisture content using both DIP and manual methods of lake soil

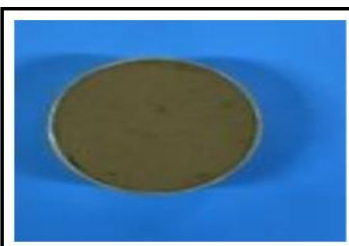

(a) wet soil pat

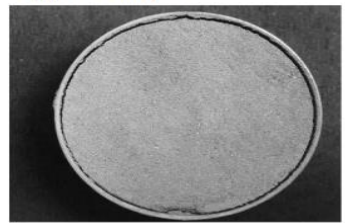

(c) Grey scale image of dry soil pat

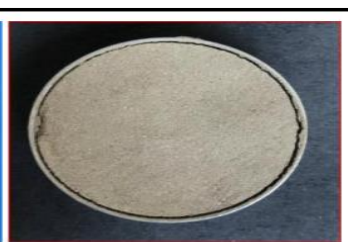

(b) dry soil pat

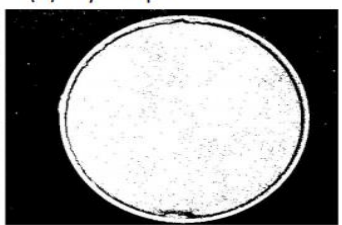

(d) Binary image with noises

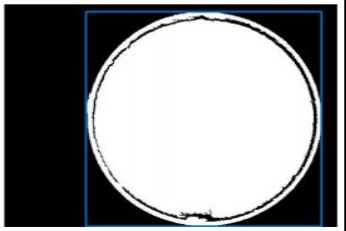

(e) Binary image with noises removed and bounding box
Fig. 12 The chronological order of pictures of lake soil leading to soil shrinkage 

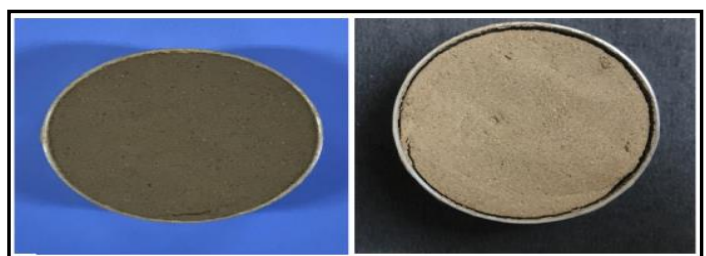

(a) Wet soil pat

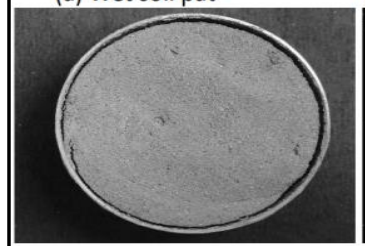

(b) Dry soil pat

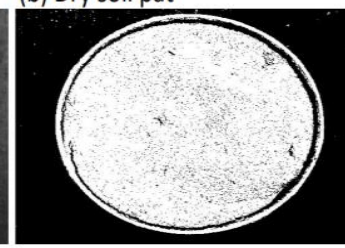

(c) Greyscale image of dry soil pat

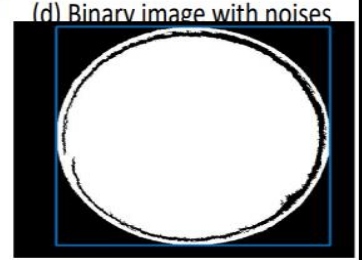

(e) Binary image with noises removed and bounding box

Fig. 13 The chronological order of pictures of BMS soil leading to soil shrinkage

Figs. 10 and 11 represent the pattern of shrinkage volume $\left(\mathrm{cm}^{3}\right)$ as the moisture content (\%) increases using both DIP and manual methods of BMS soil and lake soil using a graphical representation. Figs. 12 and 13 represent the chronological order of pictures of the lake and BMS soil respectively leading to soil shrinkage.

\section{Conclusion}

This paper deals with finding the various properties of civil engineering materials using digital image processing and compares the results with the manual methods. The initial code run check is done using a regular object to determine the accuracy of the code and to find the scale factor to convert pixels to $\mathrm{mm}$. The overall error was found to be within $10 \%$. Code is rewritten to extract information from a single irregular boulder and maximum length and breadth are extracted from the bounding box. The center of gravity of the boulder is also found concerning the origin. The error percent lies within 4-7\% when the results are compared to conventional methods. Properties of multiple aggregates are found by expanding the scope of the code. Multiple aggregates are taken from a single sample and care is taken to choose the suitable sample by grain size sieve analysis. Properties like bounding box, center of gravity, bulk volume, sphericity, elongation, and flakiness index are found. The results are compared to conventional methods and negligible error noticed in bulk volume. The elongation and flakiness index has an error. This is further extended to find the volume shrinkage in soils due to loss in moisture content by natural or artificial methods. Soils from the campus (near lake and BMS block) are collected and various soil tests are performed to determine some of the basic properties of the soils by following IS. Soil shrinkage varies for different moisture contents. So, both BMS and lake soil samples are collected, and water was mixed with varying content and placed in the oven to undergo shrinkage. This shrinkage is determined by DIP and by conventional methods (example: wax-water shrinkage limit method). The two results are compared and plotted for varying moisture content for both soils. An error of more than $10 \%$ is observed and a trend of increasing soil shrinkage with increasing moisture content is observed. This process is more accurate at finding properties of multiple aggregates over soil shrinkage. The properties found by Digital Image Processing (DIP) method are reasonably agreeable for multiple aggregates and minor percentage differences in the soil shrinkage results. It could be concluded that DIP is a non-destructible, economical, easy to use reliable method to compute the properties of civil engineering materials.

\section{References}

[1] Khaled Mahmood, Md. Raquibul Hossain, Tanvir Manzur, Ansary Shohag Nazifa Tabassum, Particle size analysis by image processing technique, BUETANWAR ISPAT 1st Bangladesh Civil Engineering Summit, Dhaka, Bangladesh, 2016, pp.124-130.

[2] Masoumeh Mokhtari, Masoud Dehghani, Swell-shrink behavior of expansive soils, damage, and control, Elect. J. Geotech. Eng. 17 (2012) 2673-2682.

[3] Lindström, Hakan, Rock property measurements using image processing, KTH Land and Water resource Engineering, Sweden, 2011.

[4] E. Romero, E. Della Vecchia, C. Jommi, An insight into the water retention properties of compacted clayey soils, Géotech. 61(4) (2011) 313-328.

[5] Taleb Al-Rousan, Eyad Masad, Erol Tutumluer, Tongyan Pan, Evaluation of image analysis techniques for quantifying aggregate shape characteristics, Constr. Build. Mater. 21(5) (2007) 978-990.

[6] J.J. Kumara, Kimitoshi Hayano, Keita Ogiwara, Image analysis techniques on evaluation of particle size distribution of gravel, Int. J. Geomate. 3(1) (2012) 290-297.

[7] B.C. Punmia, Ashok Kumar Jain, Arun Kumar Jain, Surveying III, Higher surveying, Photogrammetry surveying, Laxmi Publications (P) Ltd., New Delhi, 2017.

[8] A.K.H. Kwan, C.F. Mora, H.C. Chan, Particle shape analysis of coarse aggregate using digital image processing, Cem. Concr. Res. 29(9) (1999) 1403-1410.

[9] Pascal Boivin, Patricia Garnier, Daniel Tessier, Relationship between clay content, clay type, and shrinkage properties of soil samples, Soil Sci. Soc. Am. J. 68(4) (2004) 1145-1153.

[10] C.F. Mora, A.K.H. Kwan, Sphericity, shape factor, and convexity measurement of coarse aggregate for concrete using digital image processing, Cem. Concr. Res. $30(3)$ (2000) 351-358.

[11] N.H. Maerz, Aggregate sizing and shape determination using digital image processing, Sixth Annual Symposium Proceedings, Center for Aggregates Research (ICAR), St. Louis, Missouri,, 1998, pp.195-203.

[12] Chetana Rao, Erol Tutumluer, In Tai Kim, Quantification of coarse aggregate angularity based on image analysis, Transp. Res. Rec. 1787(1) (2002) 117-124.

[13] Nur Aisyah Kasim, N.A. Che Azmi, M. Mukri, S.N.A. Mohd Noor, Effect on physical properties of laterite soil with difference percentage of sodium bentonite, AIP Conf. Proc. 1875(1) (2017) 030003:1-6.

[14] C.F. Mora, A.K.H. Kwan, H.C. Chan, Particle size distribution analysis of coarse aggregate using digital image processing, Cem. Concr. Res. 28(6) (1998) 921 932.

[15] Radzuan Saari, Norhan Abd Rahman, H.N. Abdul Latif, Zainab Mohamed Yusof, S.K. Ngien, et al., Application of digital image processing technique in monitoring LNAPL migration in double porosity soil column, J. Teknol. 72(3) (2015) 23-29.

[16] Tamer Y. Elkady, William N. Houston, Sandra L. Houston, Calibrated image processing for unsaturated soils testing, Proceeding of the $3^{\text {rd }}$ international conference on unsaturated soils, Vol. 2, CRC Press, Recife, Brazil, 2002, pp.447451.

[17] Juan Zhang, Xin-yuan Huang, Jian Wu, Mao-jin Xie, The application of digita image processing technology in the quantitative study of the coarse aggregate shape characteristics, 2009 First international conference on information science and engineering IEEE, Nanjing, China, 2009, pp.1471-1475.

[18] Mohammed Taleb Obaidat, H.R. Al-Masaeid, Fouad Gharaybeh, Taisir Khedaywi, An innovative digital image analysis approach to quantify the percentage of voids in mineral aggregates of bituminous mixtures, Can. J. Civ. Eng. 25(6) (1998) 1041-1049.

[19] A. Kaestner, E. Lehmann, M. Stampanoni, Imaging and image processing in porous media research, Adv. Water Resour. 31(9) (2008) 1174-1187.

[20] Robert P. Chapuis, Michel Aubertin, Predicting the coefficient of permeability of soils using the Kozeny-Carman equation, Montréal, Canada, 2003. 